\title{
Predictors of outcome of subdural empyema in children
}

\author{
Subhas Konar, MCh, Dhaval Gohil, MBBS, Dhaval Shukla, MCh, Nishanth Sadashiva, MCh, \\ Alok Uppar, MCh, Dhananjaya I. Bhat, MCh, Dwarkanath Srinivas, MCh, \\ Arivazhagan Arimappamagan, MCh, and Bhagavatula Indira Devi, MCh
}

Department of Neurosurgery, National Institute of Mental Health and Neurosciences, Bangalore, India

\begin{abstract}
OBJECTIVE The aim of this study was to report the etiology, clinical features, microbiology, surgical outcome, and predictors of outcome of spontaneous subdural empyema (SDE).

METHODS The authors conducted a retrospective study in a tertiary hospital. Children up to 18 years of age, with a diagnosis of SDE with infective etiology, were included in the present cohort. Patients with posttraumatic, postsurgery, and tubercular origin of SDE were excluded from the study. The Glasgow Outcome Scale was used for outcome assessment at the end of 3 months. For analysis purposes, the demographic data, clinical features, radiological data, microbiology, type of surgery, and complication data were categorized, and univariate and multivariable logistic regression analyses were performed to identify the factors associated with outcome.
\end{abstract}

RESULTS Ninety-eight children were included in the study and the mean age was 10.9 years. Otogenic origin (34.7\%) was the most common source of infection, followed by meningitis (14.3\%). The mean duration of symptoms was 12 days. Seventy-six children presented with Glasgow Coma Scale (GCS) score > 8 and the supratentorial location was the most common location. Almost $75 \%$ of the children underwent craniotomy or craniectomy and the rest had burr-hole evacuation. Beta-hemolytic Streptococcus (10\%) was the most common organism isolated. Cerebral venous thrombosis (CVT; $10.2 \%$ ) was the most frequent complication in this cohort. The other complications were infarction (6.1\%), new-onset seizure (4.1\%), and bone flap osteomyelitis (4.1\%). Thirteen cases had a recurrence of pus collection, which was more common in the craniotomy group than in the burr-hole group. Age $(p=0.02)$, GCS score $\leq 8$ (OR $8.15, p=0.001)$, CVT (OR 15.17, $p=0.001$ ), and presence of infarction (OR $7, p=0.05)$ were strongly associated with unfavorable outcome. In multivariable logistic regression analysis, only GCS score $\leq 8(p=0.01)$, CVT $(p=0.02)$, and presence of infarction $(p=$ 0.04) had a significant impact on unfavorable outcome.

CONCLUSIONS Prompt diagnosis and immediate intervention is the goal of management of SDE, especially in children as a delay in diagnosis can result in unconsciousness and secondary complications such as CVT and infarction, which adversely affect outcome.

https://thejns.org/doi/abs/10.3171/2019.5.FOCUS19268

KEYWORDS meningitis; subdural empyema; outcome; intracranial infection

$\mathrm{S}$ UBDURAL empyema (SDE) is an acute neurological condition, especially in children. The etiopathogenesis of spontaneous SDE is spread from either local or systemic infection. The etiology also varies based on different age groups. ${ }^{8}$ The incidence of SDE in infants is approximately $1 \%-2 \%$, and is mainly due to pyogenic bacterial meningitis. ${ }^{13}$ In older children, the source is either paranasal sinus involvement ${ }^{5,15,16}$ or the mastoid. ${ }^{21}$ The pus is noted more often in the supratentorial than in the infratentorial compartment. The empyema may be over the convexity or in the interhemispheric space. Few case series $^{2,7,8,10,12,17,19,23-25}$ or case reports ${ }^{1,3,6,14,18,22}$ of SDE have been published in the literature but prognostic factors for outcome have not been analyzed. In the present study we analyzed the prognostic factors for outcome in children with SDE.

\section{Methods}

This is a retrospective study conducted at a high-volume neurosurgical center in a developing country (India). The study duration was from January 2005 to December 2017. The study was conducted within the norms of local institutional ethics policies. Children up to 18 years of age

ABBREVIATIONS CVT = cerebral venous thrombosis; GCS = Glasgow Coma Scale; GOS = Glasgow Outcome Scale; IQR = interquartile range; SDE = subdural empy-

ema.

SUBMITTED March 29, 2019. ACCEPTED May 21, 2019

INCLUDE WHEN CITING DOI: 10.3171/2019.5.FOCUS19268. 
with a diagnosis of pyogenic SDE were included in the present cohort. Patients with posttraumatic, postsurgical, and tubercular etiology of SDE were excluded from the study. Clinical data were collected from medical records, and radiological data from direct observation of images or from the medical records. The Glasgow Outcome Scale (GOS) was used at the end of 3 months from surgery to record the outcome. Outcome was dichotomized into favorable outcome, i.e., GOS score of 5 or 4 (good recovery and moderate disability), and unfavorable outcome, i.e., GOS score 1-3 (death, vegetative state, and severe disability).

\section{Prognostic Factors}

For comprehensive analyses, we considered demographic data, clinical features, radiological data, microbiology, type of surgery, and complications as prognostic factors for outcome. Age, sex (male and female), duration of symptoms ( $\leq 7$ days and $>7$ days), location (supratentorial and infratentorial), site (right and left), compartment (convexity, interhemispheric, and both), Glasgow Coma Scale (GCS) score ( $\leq 8$ and $>8$ ), preoperative seizure (present or absent), etiology related (otogenic and nonotogenic), microbiology (gram-positive and gram-negative), type of surgery (craniotomy and burr holes), and presence of cerebral venous thrombosis (CVT), infarct, cerebral abscess, and recurrence.

The Statistical Package for the Social Sciences software (version 20, IBM Corp.) was utilized for statistical analysis. To identify the association between predictive factors with the outcome, chi-square and Fisher's exact tests were performed. Both tests were utilized for categorical variables. For continuous variables, the Mann-Whitney U-test was applied. Univariate analysis (post hoc) was performed for other variables. Statistically significant variables $(\mathrm{p}<$ 0.25 ) were further considered for multivariable logistic regression analysis to identify the impact of individual risk factors. Statistical significance was defined at $p<0.05$.

\section{Results}

A total of 98 children (81 males, $82.6 \%$ ) were included in the present cohort. The mean age was 10.9 years (range 6 months-18 years). Nine children were younger than 1 year of age (Table 1).

\section{Etiology, Clinical Features, and Microbiology}

The middle ear (34.7\%) was the most common source of infection, followed by meningitis (14.3\%) and paranasal sinus (11.2\%). Twenty-eight children did not have a known source of infection. The mean duration of symptoms was 12 days and $50 \%$ of children presented within 7 days of infection. The most common symptom was fever (90.8\%) followed by headache $(65.3 \%)$ and altered sensorium $(48 \%)$. The other clinical features were seizure (35.7\%), hemiparesis (32.7\%), monoparesis (6.1\%), and cranial nerve deficits (11.2\%). Seventy-six children presented with a GCS score $>8$. The most common location was supratentorial $(84.7 \%)$ over cerebral convexity $(73.5 \%)$ collections (Fig. 1, Table 2). Ten children had associated brain abscess and 11 children had hydrocephalus. Thirty-five children had pus collection over the right hemisphere, 26 children over the left hemisphere, and 9 in the interhemi-
TABLE 1. Clinical features of the study cohort $(n=98)$

\begin{tabular}{lc}
\hline \multicolumn{1}{c}{ Parameter } & Value (\%) \\
\hline Mean age \pm SD, yrs & $10.9 \pm 5.8$ \\
\hline Males & $81(82.6)$ \\
\hline Causes & $34(34.7)$ \\
\hline Otogenic & $11(11.2)$ \\
\hline Paranasal sinusitis & $14(14.3)$ \\
\hline Meningitis & $2(2.0)$ \\
\hline Lung infection & $1(1.0)$ \\
\hline Cardiac & $8(8.2)$ \\
\hline Others & $28(28.6)$ \\
\hline Unknown & $64(65.3)$ \\
\hline Clinical features & $89(90.8)$ \\
\hline Headache & $35(35.7)$ \\
\hline Fever & $47(48)$ \\
\hline Seizures & $76(77.6)$ \\
\hline Altered sensorium & $11(11.2)$ \\
\hline GCS score $>8$ & $6(6.1)$ \\
\hline Cranial nerve deficits & $32(32.7)$ \\
\hline Monoparesis & $3(3.1)$ \\
\hline Hemiparesis &
\end{tabular}

spheric region. Beta-hemolytic Streptococcus (10\%) was the most common organism isolated, followed by alphahemolytic Streptococcus (8\%) and Proteus mirabilis (7\%). Thirty-seven children had sterile culture and 2 children had multiple organisms (Table 2).

\section{Surgical Procedures, Complications, and Outcomes}

The most common surgical procedure performed was craniotomy evacuation of pus and excision of the outer membrane (73.5\% cases; Fig. 2, Table 3). Twenty-six children underwent burr-hole evacuation of the pus collection. After the surgical evacuation of pus, all children received 2 weeks of intravenous antibiotics followed by $2-4$ weeks of oral antibiotics based on the culture sensitivity report. Children with initial sterile pus received cefotaxime, amikacin, and metronidazole based on our institute's antibiotic policy. All children with sinusitis or otitis were referred to an ear, nose, and throat surgeon for further management.

The most frequent complication of SDE was CVT $(10.2 \%)$ in our cohort. The other complications were cerebral infarction $(6.1 \%)$, new-onset seizure (4.1\%), bone flap osteomyelitis (4.1\%), wound CSF leak (2 cases), venous sinus injury ( 2 cases), and subgaleal collection of pus (1 case). Thirteen children had a recurrence of pus collection, which was more common in the craniotomy group (11 cases) versus the burr-hole group ( 2 cases; Table 3 ).

Eight children died due to septicemia in the perioperative period. One child with congenital heart disease suffered cardiac arrest after surgery, and could not be revived. Follow-up was available for 68 children, with a median follow-up duration of 14.5 months (range 3-132 months). Two children developed hydrocephalus at follow- 

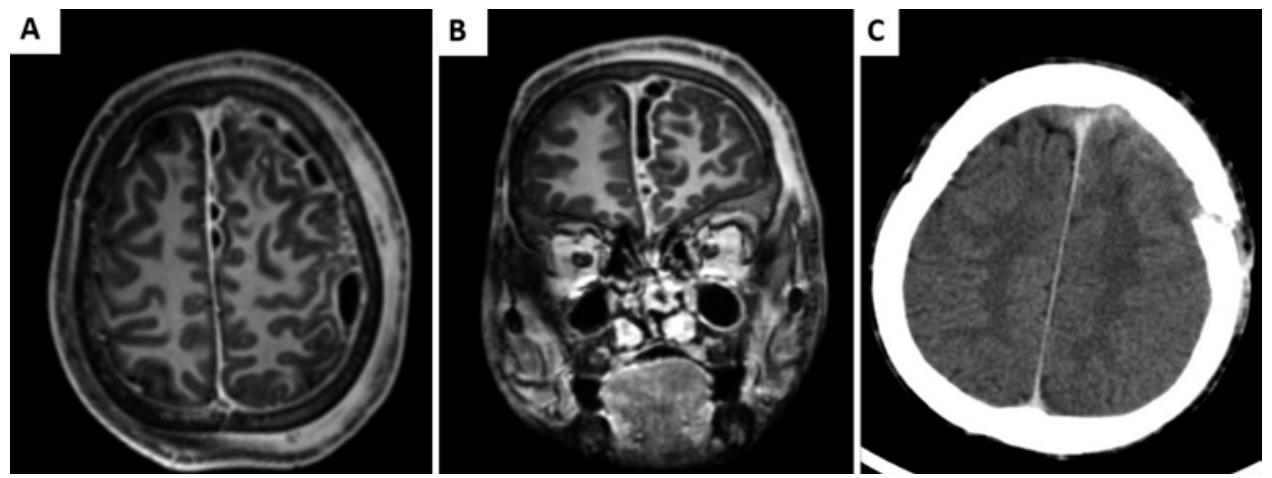

FIG. 1. A: Axial T1-weighted MR image with contrast enhancement showing a left-sided, frontoparietal, subdural, hypointense collection with peripheral enhancement, suggestive of pus collection. B: Coronal T1-weighted MR image with contrast enhancement showing an interhemispheric pus collection in continuation with the convexity. C: Axial CT image with contrast enhancement showing good evacuation of the pus collection and evidence of craniotomy.

up and underwent ventriculoperitoneal shunt insertion. At 3 months after surgery, 63 children $(82.9 \%)$ had a favorable outcome and $13(17.1 \%)$ had an unfavorable outcome, including the 8 perioperative deaths.

\section{Prognostic Factors for Unfavorable Outcome}

Univariate and multivariable logistic regression analyses were used to identify factors associated with unfavorable outcome (Tables 4 and 5). The median age (interquartile range [IQR]) of the children with favorable outcome was 13 years (IQR 8-16 years) and for unfavorable outcome was 5 years (IQR 2.5-13 years). Age $(\mathrm{p}=0.02)$, GCS score $\leq 8$ (OR 8.15, $\mathrm{p}=0.001)$, CVT (OR 15.17, $\mathrm{p}=$ 0.001 ), and presence of infarction (OR 7, $\mathrm{p}=0.05)$ were strongly associated with unfavorable outcome. On multivariable logistic regression analysis, only GCS score $\leq 8$ $(\mathrm{p}=0.01)$, CVT $(\mathrm{p}=0.02)$, and presence of infarction ( $\mathrm{p}$ $=0.04$ ) had a significant impact on unfavorable outcome (Table 5).

\section{Discussion}

The current study is one of the largest series of SDE in children across all age groups and etiologies. The predictors of unfavorable outcome were also studied. The results of our study were compared with other series (Table 6). ${ }^{2,8-10,17,24,25}$ In our cohort, the mean age was 10.9 years (range 6 months-18 years), which was consistent with the reported literature (Table 6). Male children were more affected than female children in our study, which is also consistent with the published literature. ${ }^{13}$ In our cohort, $34.7 \%$ of cases were due to otogenic origin and $14.3 \%$ were due to sequelae of meningitis. All infants (9 cases) had meningitis prior to development of SDE. The source of infection for SDE varies according to patient age..$^{8}$ In an infant, the common source was secondary infection of a subdural collection following bacterial meningitis. ${ }^{9}$ The otogenic source was the predominant origin in both the supratentorial and infratentorial compartment, although the paranasal sinus was the second most common source in the supratentorial compartment, ${ }^{13}$ especially in older children. These findings are also similar to those in previous studies.
The SDE presents with either systemic manifestation such as fever or symptoms related to the source of infection, or neurological symptoms such as seizures, altered sensorium, and focal neurological deficits. ${ }^{4}$ In developing countries it is not uncommon for children to present in altered sensorium to a neurosurgeon. In older series, 57\%$74.1 \%$ of children presented in altered sensorium..$^{2,10,25} \mathrm{In}$ our study, the median GCS score at presentation was 13

TABLE 2. Radiology and microbiology

\begin{tabular}{|c|c|}
\hline Parameter & Value $(\%)$ \\
\hline \multicolumn{2}{|l|}{ Radiology } \\
\hline Supratentorial & $83(84.7)$ \\
\hline Convexity & $61(73.5)$ \\
\hline Convexity \& interhemispheric & $13(15.7)$ \\
\hline Interhemispheric & $9(10.8)$ \\
\hline Infratentorial & $15(15.3)$ \\
\hline Associated abscess & $10(10.2)$ \\
\hline Hydrocephalus & $11(11.2)$ \\
\hline \multicolumn{2}{|l|}{ Microbiology } \\
\hline S. aureus & $4(4.1)$ \\
\hline S. epidermidis & $5(5.1)$ \\
\hline Alpha-hemolytic Streptococcus & $8(8.2)$ \\
\hline Beta-hemolytic Streptococcus & $10(10.2)$ \\
\hline Acinetobacter baumannii & $1(1.0)$ \\
\hline NFGNB & $2(2.0)$ \\
\hline Enterobacter & $1(1.0)$ \\
\hline Escherichia coli & $7(7.1)$ \\
\hline Pseudomonas spp. & $6(6.1)$ \\
\hline Proteus spp. & $7(7.1)$ \\
\hline Klebsiella & $2(2.0)$ \\
\hline Peptostreptococcus & $3(3.1)$ \\
\hline Providentia & $1(1.0)$ \\
\hline Anaerobic bacteria & $2(2.0)$ \\
\hline Multiple organisms & $2(2.0)$ \\
\hline Sterile & $37(37.8)$ \\
\hline
\end{tabular}

NFGNB = nonfermenting gram-negative bacilli. 

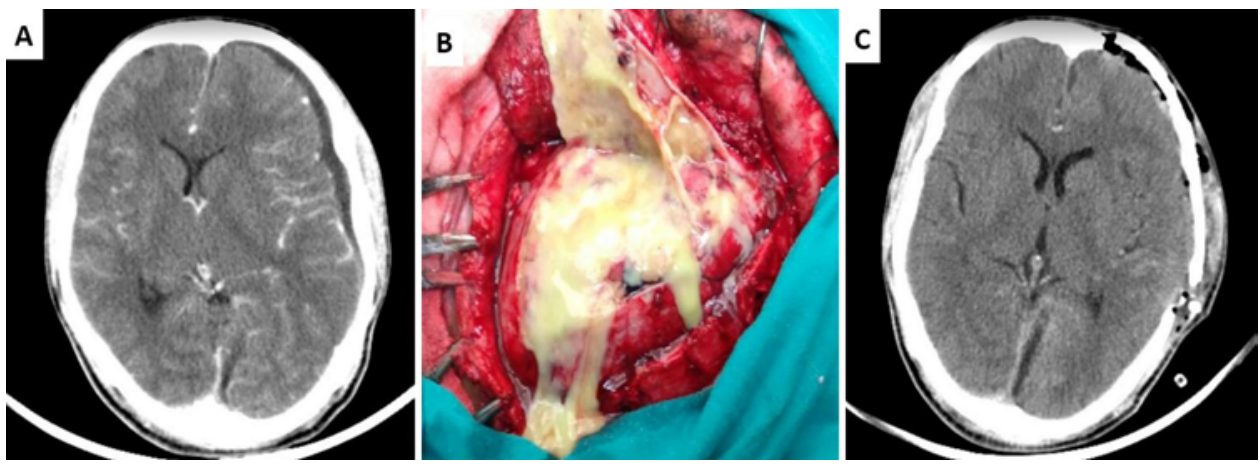

FIG. 2. A: Axial CT image with contrast showing a left-sided, frontal, hypodense collection. B: Intraoperative photograph showing the yellowish pus collection underneath the dura. C: Axial CT image with contrast showing good evacuation of pus.

and $22.4 \%$ presented with GCS scores $\leq 8$. The lower incidence of altered sensorium in our series was due to ease of access to CT scans in the last decade in our city, leading to early diagnosis.

In the present antibiotic area, the number of sterile culture reports is rising. In the previous series the sterile culture was reported in $14 \%-35.4 \% .^{2,10,25}$ In our cohort, the incidence of sterile culture was $37.8 \%$. The organisms isolated depend on the source and age of the child. In a series of infants, or predominantly infants, the organisms isolated were Haemophilus influenza, S. aureus, and Streptococcus. ${ }^{9,24,25}$ In the present series the most common organism isolated was Streptococcus, and the most common source was otogenic.

\section{Surgical Management and Complications}

Commonly craniotomy or craniectomy is the procedure of choice for SDE, ${ }^{11}$ but if the child is severely ill or not

TABLE 3. Surgery, complications, and outcomes

\begin{tabular}{lc}
\hline \multicolumn{1}{c}{ Parameter } & Value (\%) \\
\hline Surgical procedure & $26(26.5)$ \\
\hline Burr hole & $72(73.5)$ \\
\hline Craniotomy/craniectomy & $2(2.0)$ \\
\hline Shunt for persisting hydrocephalus \\
\hline Complication \\
\hline CVT & $10(10.2)$ \\
\hline New-onset seizures & $4(4.1)$ \\
\hline Infarction & $6(6.1)$ \\
\hline Subgaleal pus collection & $1(1.0)$ \\
\hline Wound CSF leak & $2(2.0)$ \\
\hline Venous sinus injury & $2(2.0)$ \\
\hline Bone flap osteomyelitis & $4(4.1)$ \\
\hline Outcome & $13(13.3)$ \\
\hline Recurrence & $2 / 26(7.7)$ \\
\hline Burr-hole group & $11 / 72(15.3)$ \\
\hline Craniotomy group & $8(10.7)$ \\
\hline Death & $63 / 76(82.9)$ \\
\hline Favorable outcome & $13 / 76(17.1)$ \\
\hline Unfavorable outcome (including death)
\end{tabular}

fit for craniotomy, then burr-hole evacuation is an option. In our institute as well, craniotomy is the preferred treatment for SDE. In our study, $73.5 \%$ of children underwent craniotomy/craniectomy and $26.5 \%$ burr-hole evacuation. The recurrence rate was greater in the burr-hole group compared with the craniotomy group. ${ }^{7}$ Liu et al. ${ }^{9}$ reported no difference in either group. In our study, we found that the recurrence rate was greater in the craniotomy group (11 cases) than in the burr-hole group ( 2 cases). The reasons for greater recurrence in the craniotomy/craniectomy group in our cohort were sterile culture resulting in administration of nonspecific antibiotics, a larger number of interhemispheric collections, delay in treatment of the primary source (otogenic source), and thicker collection of pus. In contrast, children who underwent burr-hole evacu-

TABLE 4. Univariate analysis for unfavorable outcome

\begin{tabular}{|c|c|c|}
\hline Variable & $\begin{array}{c}\text { OR }(95 \% \mathrm{Cl}) \text { for } \\
\text { Unfavorable Outcome }\end{array}$ & $\mathrm{p}$ Value \\
\hline Age & $241^{*}$ & 0.02 \\
\hline Sex: male vs female & $1.29(0.27-9.55)$ & 0.80 \\
\hline Duration: $<7$ vs $>7$ days & $1.98(0.57-7.3)$ & 0.28 \\
\hline $\begin{array}{l}\text { Location: supratentorial vs infraten- } \\
\text { torial }\end{array}$ & $1.98(0.28-47.69)$ & 0.59 \\
\hline Side: rt vs It & $2.09(0.50-10.85)$ & 0.32 \\
\hline $\begin{array}{l}\text { Supratentorial: convexity vs inter- } \\
\text { hemispheric }\end{array}$ & $1.13(0.11-11.18)$ & 0.98 \\
\hline GCS score: $\leq 8$ vs $>8$ & $8.15(2.20-32.81)$ & 0.001 \\
\hline Source: otogenic vs nonotogenic & $1.71(0.31-10.13)$ & 0.53 \\
\hline $\begin{array}{l}\text { Microbiology: sterile vs organism } \\
\text { isolated }\end{array}$ & $2.31(0.60-11.3)$ & 0.23 \\
\hline Surgery: burr hole vs craniotomy & $1.70(0.45-6.44)$ & 0.63 \\
\hline Symptoms: seizure vs no seizure & $3.36(0.80-14.12)$ & 0.16 \\
\hline Complication: CVT vs no CVT & $15.17(3.05-75.3)$ & 0.001 \\
\hline Complication: infarct vs no infarct & $7.0(0.92-67.92)$ & 0.05 \\
\hline $\begin{array}{l}\text { Association lesion: abscess vs no } \\
\text { abscess }\end{array}$ & $2.08(0.25-12.09)$ & 0.34 \\
\hline Recurrence vs no recurrence & $1.04(0.10-10.18)$ & 0.91 \\
\hline Hydrocephalus vs no hydrocephalus & $1.87(0.24-47.02)$ & 0.63 \\
\hline
\end{tabular}


TABLE 5. Regression analysis of predictive factors for unfavorable outcome

\begin{tabular}{lclc}
\hline \multicolumn{1}{c}{ Predictors } & $\operatorname{Exp}(\mathrm{B})$ & \multicolumn{1}{c}{$95 \% \mathrm{Cl}$} & $\mathrm{p}$ Value \\
\hline Age & 0.823 & $0.67-1.01$ & 0.06 \\
\hline GCS score $\leq 8$ vs $>8$ & 28.59 & $2.21-370.08$ & $\mathbf{0 . 0 1}$ \\
\hline No CVT vs CVT & 0.06 & $0.006-0.69$ & $\mathbf{0 . 0 2}$ \\
\hline No infarct vs infarct & 0.03 & $0.001-0.91$ & $\mathbf{0 . 0 4}$ \\
\hline Seizure vs no seizure & 0.78 & $0.08-7.37$ & 0.83 \\
\hline Sterile vs organism isolated & 0.47 & $0.04-5.26$ & 0.54 \\
\hline
\end{tabular}

Exp $(B)=$ exponentiation of the $B$ coefficient.

The correct classification rate of the above fitted model is $87.3 \%$. Boldface type indicates statistical significance.

ation were more often infants, had less-thick collections, and the etiology was more often postmeningitis. The morbidities of SDE are hemiparesis (15\%-35\%) and persistent seizures $(12 \%-37.5 \%)$, and the reported mortality rate is $3 \%-10.8 \%$ (Table 6).

The complications encountered in our series were CVT $(10.2 \%)$, venous sinus injury $(2.0 \%)$, arterial infarction (6.1\%), and bone flap osteomyelitis (4.1\%). The mortality rate in our cohort was $10.7 \%$. The higher mortality rate in our series was due to a significant proportion of children presenting in a coma.

\section{Predictors of Outcome}

We studied a number of predictors of outcome using regression analyses. The predictors of outcome have not been widely reported. We found that younger age, presentation in coma (GCS score $\leq 8$ ), and complications (CVT and infarction) were significantly associated with unfavorable outcome (death, severe disability, vegetative state) at follow-up. The correct classification rate of the fitted model was $87.3 \%$. The commonly perceived predictors of poor outcome such as infratentorial location, duration of symptoms, presence of abscess, associated hydrocephalus, type of surgery, organisms isolated, and recurrence were not found to be significant in our study.

Other studies have reported a few predictors of outcome. Legrand et al. found that age $>1$ year was associated with poor outcome. ${ }^{8}$ The infants had SDE as a sequelae of meningitis, which responds well to antibiotics. They also found that neurological deficit at the time of admission was one of the significant predictors of outcome. ${ }^{8}$ In a literature review, ${ }^{13}$ the occurrence of aerobic streptococci was found to be a good prognostication factor and the presence of sterile culture was the poor factor for outcome. However, in our study, outcome was not related to the isolated organisms in the culture. A few studies $^{14,20}$ have shown inferior outcome in infratentorial SDE as compared to supratentorial SDE due to rapid progression of disease. However, outcome was not related to location of SDE in our series. Complications of SDE such as CVT and hydrocephalus may influence outcome. Legrand et al. reported CVT to be a strong independent predictor of inferior outcome. ${ }^{8}$ Similarly, in our cohort, occurrence of CVT was associated with unfavorable outcome. In addition, CVT arterial infarction was strongly correlated with unfavorable outcome in our series. The presence of

TABLE 6. Literature review of published series of SDE in children

\begin{tabular}{|c|c|c|c|}
\hline Authors \& Year & Study Details & Predictors & Outcome \\
\hline Madhugiri et al., 2011 & $\begin{array}{l}27 \text { pts, only infratentorial location, mean age } \\
9.8 \text { yrs, sterile culture } 25.9 \%\end{array}$ & $\begin{array}{l}\text { GCS motor score }<M 6 \text {, presence of } \\
\text { hydrocephalus on primary scan, burr } \\
\text { hole as 1st op = unfavorable outcome }\end{array}$ & Favorable $92.5 \%$, death $3.7 \%$ \\
\hline Liu et al., 2010 & $\begin{array}{l}33 \text { pts, only infants, etiology = post meningi- } \\
\text { tis, Hemophilus influenzae most common } \\
(32.3 \%)\end{array}$ & $\begin{array}{l}\text { Early detection \& evacuation of pus = } \\
\quad \text { favorable outcome }\end{array}$ & Favorable $73 \%$, death $3 \%$ \\
\hline Legrand et al., 2009 & $\begin{array}{l}33 \text { pts, median age } 10.5 \text { yrs, gram-positive } \\
\text { cocci most common organism }\end{array}$ & $\begin{array}{l}\text { Neurological deficit on admission, } \\
\text { cerebral thrombophlebitis, cerebral } \\
\text { herniation, age }>1 \mathrm{yr}=\text { unfavorable } \\
\text { outcome }\end{array}$ & Favorable $82 \%$, death $4 \%$ \\
\hline Banerjee et al., 2009 & $\begin{array}{l}65 \text { pts, only supratentorial location, mean } \\
\text { age } 9.5 \text { yrs, sterile } 35.4 \%\end{array}$ & Postop CVT = unfavorable outcome & Favorable $87 \%$, death $10.8 \%$ \\
\hline Wu et al., 2008 & $\begin{array}{l}31 \text { pts, infants } 87.1 \% \text {, etiology = head } \\
\text { trauma or op } 19.4 \%, \text { S. pneumonia most } \\
\text { common organism }\end{array}$ & Not reported & $\begin{array}{l}\text { Good recovery (w/o neurological } \\
\text { sequelae) } 38.7 \% \text {, death } 9.7 \%\end{array}$ \\
\hline Yilmaz et al., 2006 & $\begin{array}{l}28 \text { pts, average age } 10 \text { mos, etiology = } \\
\text { bacterial meningitis, } S \text {. aureus most com- } \\
\text { mon organism }\end{array}$ & $\begin{array}{l}\text { Craniotomy had better outcome com- } \\
\text { pared to burr hole }\end{array}$ & No deaths \\
\hline Pattisapu \& Parent, 1987 & $8 \mathrm{pts}$, mean age $5.7 \mathrm{yrs}$ & Not reported & Good recovery $62 \%$, no deaths \\
\hline Present study & $\begin{array}{l}98 \text { pts, mean age } 10.9 \mathrm{yrs} \text {, most common } \\
\text { etiology = otogenic, beta-hemolytic Strep- } \\
\text { tococcus most common organism }\end{array}$ & $\begin{array}{l}\text { GCS score }<8, \text { presence of CVT \& infarct } \\
=\text { unfavorable outcome }\end{array}$ & Favorable $82.9 \%$, death $10.7 \%$ \\
\hline
\end{tabular}

Pts $=$ patients 
hydrocephalus is a poor prognostication factor according to the literature, ${ }^{10}$ but in our study it did not influence the outcome.

\section{Study Limitations}

Although the present series reports one of the highest numbers of pediatric cases of SDE, it is not devoid of the pitfalls of a retrospective study. We have not included the immune status of the children, the general health of children, management of complications, and socioeconomic status of the family in our analysis. We have combined all the cases across various age groups and etiologies. The number of infants was low in our series, thus we could not perform a subgroup analysis.

\section{Conclusions}

Younger age, poor GCS score at presentation, occurrence of CVT, and arterial infarction were poor prognostic factors for outcome of spontaneous SDE. Early surgical intervention and evacuation of pus with proper antibiotic coverage should be the goal of management.

\section{References}

1. Bako W, Raczkowska-Kozak J, Liberek A, Góra-Gebka M: Subdural empyemas - a rare complication of meningococcal cerebrospinal meningitis in children. Med Sci Monit 6:1008-1012, 2000

2. Banerjee AD, Pandey P, Devi BI, Sampath S, Chandramouli BA: Pediatric supratentorial subdural empyemas: a retrospective analysis of 65 cases. Pediatr Neurosurg 45:11-18, 2009

3. Bouziri A, Khaldi A, Smaoui H, Menif K, Ben Jaballah N: Fatal subdural empyema caused by Streptococcus constellatus and Actinomyces viscosus in a child-case report. J Microbiol Immunol Infect 44:394-396, 2011

4. Bruner DI, Littlejohn L, Pritchard A: Subdural empyema presenting with seizure, confusion, and focal weakness. West J Emerg Med 13:509-511, 2012

5. Germiller JA, Monin DL, Sparano AM, Tom LW: Intracranial complications of sinusitis in children and adolescents and their outcomes. Arch Otolaryngol Head Neck Surg 132:969-976, 2006

6. Gupta A, Karanth SS, Raja A: Infratentorial subdural empyemas mimicking pyogenic meningitis. J Neurosci Rural Pract 4:213-215, 2013

7. Hendaus MA: Subdural empyema in children. Glob J Health Sci 5:54-59, 2013

8. Legrand M, Roujeau T, Meyer P, Carli P, Orliaguet G, Blanot $\mathrm{S}$ : Paediatric intracranial empyema: differences according to age. Eur J Pediatr 168:1235-1241, 2009

9. Liu ZH, Chen NY, Tu PH, Lee ST, Wu CT: The treatment and outcome of postmeningitic subdural empyema in infants. $\mathbf{J}$ Neurosurg Pediatr 6:38-42, 2010

10. Madhugiri VS, Sastri BV, Bhagavatula ID, Sampath S, Chandramouli BA, Pandey P: Posterior fossa subdural empyema in children-management and outcome. Childs Nerv Syst 27:137-144, 2011

11. Mat Nayan SA, Mohd Haspani MS, Abd Latiff AZ, Abdullah JM, Abdullah S: Two surgical methods used in 90 patients with intracranial subdural empyema. J Clin Neurosci 16:1567-1571, 2009
12. Md Ralib AR, Ariff AR, Shuaib IL, Naing NN, George PJ, Abdullah JM: Analysis of pediatric subdural empyema outcome in relation to computerized tomography brain scan. Southeast Asian J Trop Med Public Health 35:434-444, 2004

13. Muzumdar D, Biyani N, Deopujari C: Subdural empyema in children. Childs Nerv Syst 34:1881-1887, 2018

14. Neromyliotis E, Giakoumettis D, Drosos E, Nikas I, Blionas A, Sfakianos G, et al: Pediatric infratentorial subdural empyema: a case report. Surg Neurol Int 9:104, 2018

15. Osman Farah J, Kandasamy J, May P, Buxton N, Mallucci C: Subdural empyema secondary to sinus infection in children. Childs Nerv Syst 25:199-205, 2009

16. Patel NA, Garber D, Hu S, Kamat A: Systematic review and case report: Intracranial complications of pediatric sinusitis. Int J Pediatr Otorhinolaryngol 86:200-212, 2016

17. Pattisapu JV, Parent AD: Subdural empyemas in children. Pediatr Neurosci 13:251-254, 1987

18. Sengül G: Infratentorial subdural empyema. Turk Neurosurg 19:200-202, 2009

19. Smith HP, Hendrick EB: Subdural empyema and epidural abscess in children. J Neurosurg 58:392-397, 1983

20. van de Beek D, Campeau NG, Wijdicks EF: The clinical challenge of recognizing infratentorial empyema. Neurology 69:477-481, 2007

21. Vazquez E, Castellote A, Piqueras J, Mauleon S, Creixell S, Pumarola F, et al: Imaging of complications of acute mastoiditis in children. Radiographics 23:359-372, 2003

22. Williams V, Lakshmikantha KM, Nallasamy K, Sudeep KC, Baranwal AK, Jayashree M: Subdural empyema due to Salmonella paratyphi B in an infant: a case report and review of literature. Childs Nerv Syst 34:2317-2320, 2018

23. Wong AM, Zimmerman RA, Simon EM, Pollock AN, Bilaniuk LT: Diffusion-weighted MR imaging of subdural empyemas in children. AJNR Am J Neuroradiol 25:1016-1021, 2004

24. Wu TJ, Chiu NC, Huang FY: Subdural empyema in children-20-year experience in a medical center. J Microbiol Immunol Infect 41:62-67, 2008

25. Yilmaz N, Kiymaz N, Yilmaz C, Bay A, Yuca SA, Mumcu C, et al: Surgical treatment outcome of subdural empyema: a clinical study. Pediatr Neurosurg 42:293-298, 2006

\section{Disclosures}

The authors report no conflict of interest concerning the materials or methods used in this study or the findings specified in this paper.

\section{Author Contributions}

Conception and design: Konar, Sadashiva. Acquisition of data: Konar, Gohil. Analysis and interpretation of data: Shukla, Konar. Drafting the article: Konar. Critically revising the article: Shukla, Konar. Reviewed submitted version of manuscript: Shukla, Konar. Approved the final version of the manuscript on behalf of all authors: Shukla. Statistical analysis: Shukla, Konar. Administrative/technical/material support: Sadashiva, Uppar, Bhat, Srinivas, Arimappamagan, Devi. Study supervision: Devi.

\section{Correspondence}

Dhaval Shukla: NIMHANS, Bangalore, India.neurodhaval@ rediffmail.com. 